\section{UNIVERSITY OF CALIFORNIA \\ COLLEGE OF AGRICULTURE \\ BERKELEY}

AGRICULTURAL EXPERIMENT STATION

BENJ. IDE WHEELER, PRESIDENT

THOMAS FORSYTH HUNT, DEANAND DIRECTOR

H. E. VAN NORMAN, VICE-DIRECTOR AND DEAN UNIVERSITY FARM SCHOOL

CIRCULAR No. 213

MAY, 1919

\title{
EVAPORATORS FOR PRUNE DRYING
}

\author{
BY W. V. CRUESS
}

\section{CONTENTS}

A. Theory of Evaporation

PAGE

B. General Principles of Various Types of Eyaporators

1. Defects of Some Present Evaporators ............................................. 3

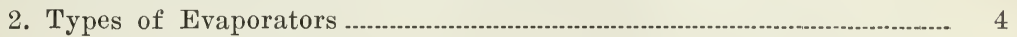

(a) Air Blast Evaporator .......................................................... 4

(b) Evaporators Depending upon Ventilators for Air Circulation 4

(c) Vacuum Evaporators ............................................................ 5

C. Construction and Use of Evaporators ............................................................... 5

1. The Oregon Tunnel Evaporator ........................................................... 5

(a) General Specifications of a Tunnel Evaporator ..................... 7

(b) Cost of Tunnel Evaporator ............................................. 9

(c) Discussion of Oregon Tunnel Evaporator ............................. 10

(d) Operation of the Evaporator ........................................... 14

2. Air-Blast Evaporator ............................................................... 14

(a) General Specifications of Air-Blast Evaporator .................... 14

(b) Cost of Air-Blast Evaporator ....................................... 17

(c) Discussion of Air-Blast Evaporator ............................... 18

(d) Operation of Air-Blast Evaporator ........................................ 21

3. The Young Evaporator ................................................................................. 22

(a) General Specifications of Young Evaporator ........................ 22

(b) Cost of Young Evaporator ................................................... 24

(c) Discussion of Young Evaporator ................................................ 24

(d) Operation of Young Evaporator .......................................... 25

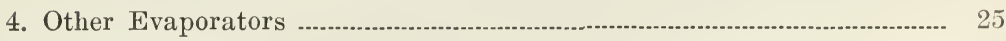

(a) Kiln Evaporator ............................................................. 25

(b) Watsonville Stack Evaporator .............................................. 27

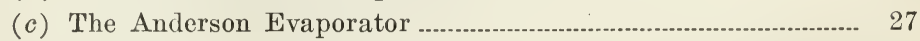

(d) Commercially Built Evaporators ........................................... 28

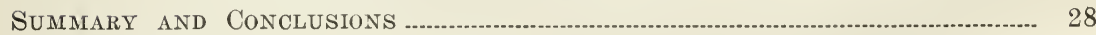

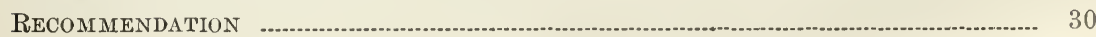


In years when early rains occur during the prune-drying season, loss of fruit sometimes occurs because of the failure of the usual sun-drying methods. Various methods of supplementing sun-drying during such emergencies are in use, one of the best being that of sulfuring described in Circular 211.

Better results are obtained, however, under such circumstances by the use of dryers or evaporators. It is also often desirable to supplement sulfuring with these evaporators. The initial cost of an evaporator may appear large but the loss during one season, such as that of 1918, would be several times greater than this cost. The number of evaporators in the prune-growing districts of the state is too small and many of those in use are inefficient.

This circular gives the results of a study of the principal evaporators in California and of the literature on the subject. It was found that fundamental principles of artificial evaporation have been neglected in most of the evaporators now used in our prune-drying yards. As a result of our investigations, we are enabled to recommend remedies for some of these defects and to suggest a better design for new evaporators.

A short discussion of the theory of evaporation will give a clearer understanding of the general principles.

\section{A. THEORY OF EVAPORATION}

Evaporation is the change of water from the liquid to the gaseous or vapor state. It is influenced by heat and by dryness of the air. The heat used may be that occurring naturally, as a result of radiation from the sun, or that obtained by the burning of fuel. The moisture evaporated by heat is absorbed and carried away by the atmosphere. The higher the temperature the more moisture the atmosphere can hold. At a temperature of $101^{\circ} \mathrm{F}$. it will require 349 cubic feet of the atmosphere to absorb one pound of water vapor; at $128^{\circ} \mathrm{F}$. the same volume of air would hold, at saturation, two pounds of water vapor; the same volume of air at $156^{\circ} \mathrm{F}$. would absorb four pounds of water vapor. Every $27^{\circ} \mathrm{F}$. rise in temperature doubles the moisture-absorbing power of the atmosphere.

The atmosphere is always more or less humid; that is, contains some water vapor. The less moisture it contains, the more it can absorb at a given temperature. A volume of 349 cubic feet of air at $101^{\circ} \mathrm{F}$. and 10 per cent humidity can still absorb .9 pound of water vapor, while the same volume of air at $101^{\circ} \mathrm{F}$. and 50 per cent humidity can only absorb .5 pound of water vapor. In order that evaporation may be rapid and continuous, the saturated air must be removed; therefore movement of drier air through the evaporator is essential.

As the evaporation of moisture requires heat, the heat absorbed from the air during evaporation causes a lowering of the temperature of the air. This drop in temperature lowers the moisture-absorbing power of the air so that the amount of moisture that the air will absorb is less than that which it would absorb if the temperature could be held constant at the higher level. Moreover, as the 
atmosphere approaches the point of saturation, evaporation becomes slow, so that it is not economical to try to utilize all of its drying power. This results in a loss of a large amount of heat. Some heat is taken up by the article dried, the walls of the evaporator, and by other articles that come in contact with the air.

If air is taken in at $90^{\circ} \mathrm{F}$., heated to $150^{\circ} \mathrm{F}$., and passes out of the evaporator at $120^{\circ} \mathrm{F}$., the air is heated $60^{\circ} \mathrm{F}$. and drops only $30^{\circ} \mathrm{F}$. In this case 50 per cent of the heat is unused.

Tests by heating and ventilating engineers indicate that on the average only about 40 per cent of the heat furnished to an evaporator is utilized. Theoretically, the heat generated by one pound of oil will evaporate about 18 pounds of water, but in practice it evaporates only about $71 / 4$ pounds.

Other things being equal, the rate of evaporation is more or less proportional to the temperature and the volume of air passing through the evaporator. However, it is possible by raising the temperature to reach a point where the water from the interior of the fruit can not diffuse to the surface as rapidly as it is absorbed. This results in "case hardening" or drying out and partial sealing of the surface of the fruits, with a decrease in the rate of drying.

There is a temperature above which all fruits, when dry, deteriorate rapidly. For prunes this temperature is believed to be about $150^{\circ} \mathrm{F}$. It is spoken of as the "critical temperature."

\section{B. GENERAL PRINCIPLES OF VARIOUS TYPES OF EVAPORATORS}

1. Defects of Some Present Evaporators.-A large volume of air of low humidity is necessary for rapid evaporation. Many evaporators do not provide this condition. In some evaporators, the air is made to circulate over the fruit again and again with the result that it becomes saturated with moisture and merely cooks the fruit without drying it. Such evaporators provide no inlet for outside air and no outlet for the saturated air. In other evaporators the apertures for entrance of fresh air and escape of spent air are altogether too small in proportion to the size of the evaporator.

Often the air circulation in the evaporator is not uniform; trays of fruit near the floor drying more or less rapidly than those at other levels. This makes shifting of the trays necessary and increases the labor cost. In other driers, large channels are left beside the stacks of trays. The air tends to flow through these spaces rather than over the fruit.

In some evaporators, the heat supply is very inadequate. If the air is passed rapidly its temperature will be low; if passed slowly its temperature may be high enough but its volume will be small. In either case the evaporation will be small. The furnace or other heating device should produce enough heat and the radiating surface should be large enough to deliver this heat to the air without waste. The heat generated in the furnace should not be allowed to escape through the smokestack. Where flues are used to heat the air, they 
have in most cases altogether too little radiating surface. Fires have been caused by overheating such flues in an attempt to force them beyond their capacity.

Most California evaporators are equipped with poor thermometers or none at all. Accurate thermometers, if possible, recording thermometers, should be installed in order that the operator may know the correct or exact temperature inside the evaporator.

2. Types of Evaporators.-There are, in general, three types of evaporators for fruits, viz., (a) forced draft or air blast evaporators, (b) evaporators depending on ventilators for air circulation, and (c) vacuum evaporators. The last named type is not in common use for fruits and is too expensive for general fruit evaporation.

(a) Air Blast Evaporator: Usually this evaporator consists of a long horizontal or nearly horizontal chamber or tunnel in which the fruit is placed for drying. A fan blows or draws air through a heating system located at one end of the tunnel and forces the heated air through the drying chamber.

The fan may be of the positive blower type, in which case the air heater and fan are located at the same end of the evaporator; or it may be of the exhaust or suction type, in which case the air is drawn through the evaporator and the air heating system is located at the end opposite the fan. The positive blower type is most common, but the exhaust fan is believed to produce a more uniform current of air throughout the length of the evaporator.

The drying chamber may connect with a ventilator which tends to increase the flow of air. The ventilator in such installations is of secondary importance, provided it is not so narrow that it retards rather than aids air flow.

The air heating system is most often composed of steam coils over which the air is drawn or blown by a fan. The temperature of the air can be closely regulated by controling the pressure or amount of steam used. Another system in common use consists of a furnace and large flues enclosed in a fire-proof room. Air is drawn over the flues by a fan. This type of construction is cheaper than that employing steam coils and can be made to operate as efficiently.

(b) Evaporators Depending upon Ventilators for Air Circulation: The design of this type varies greatly, but air circulation is accomplished in all by means of ventilators and natural draft. The ventilator consists of a tall stack connected to the drying compartment. It produces a draft through the evaporator, in the same way that an ordinary furnace stack or stovepipe creates a draft through a furnace or stove. The taller the ventilator the stronger the draft. 
The heating system is located below the material to be dried. Thus, the heated air, being lighter than the surrounding outside air, rises through the drying chamber and after taking up moisture escapes through the ventilator. The heat may be supplied by a furnace and flues or by a steam plant and steam pipes. The former system is the one most commonly employed.

Air is admitted at the bottom of the air heating chamber and the amount admitted is so regulated that the desired temperature is maintained in the evaporator. For a given temperature, the rate of evaporation will be proportional to the air flow within certain limits.

The ordinary hop kiln, the Oregon prune tunnel, the steam coil cabinet evaporator, and the stack evaporator are all of this type. Examples of these are described later.

(c) Vacuum Evaporators: These are used in drying certain chemicals and substances easily injured by heat or air. Under a vacuum, evaporation proceeds at a much lower temperature than under atmospheric pressure. Fruit can be evaporated very rapidly at $100^{\circ} \mathrm{F}$. in a vacuum evaporator. Oxidation by air which takes place in ordinary evaporators is very greatly reduced. Consequently, a product of fresh flavor and appearance can be produced by this method. The construction of vacuum evaporators is, however, very expensive and a great deal of skill and experience is necessary for their successful operation. They are not recommended for prune drying.

\section{CONSTRUCTION AND USE OF EVAPORATORS}

The style and size of evaporator to be constructed will vary with the size of the dry-yard and with the personal preference of the builder. The Oregon tunnel evaporator has been found very satisfactory in Oregon and will probably answer the needs of the dryyard of average size as well as any other form that could be built. For the large dry-yard, an air-blast type of dryer will probably be most useful. For the small yard an inexpensive evaporator, such as the Young evaporator or the New Way evaporator, is desirable.

Descriptions and specifications for (1) an Oregon prune tunnel evaporator, (2) an air blast evaporator, and (3) a small stack evaporator are given below.

1. The Oregon Tunnel Evaporator.-This evaporator is used very extensively in Oregon and Washington for drying the fresh fruit as it comes from the orchard.

In a general way, the tunnel evaporator may be described as a series of parallel, nearly horizontal narrow chambers, above a firepit. 

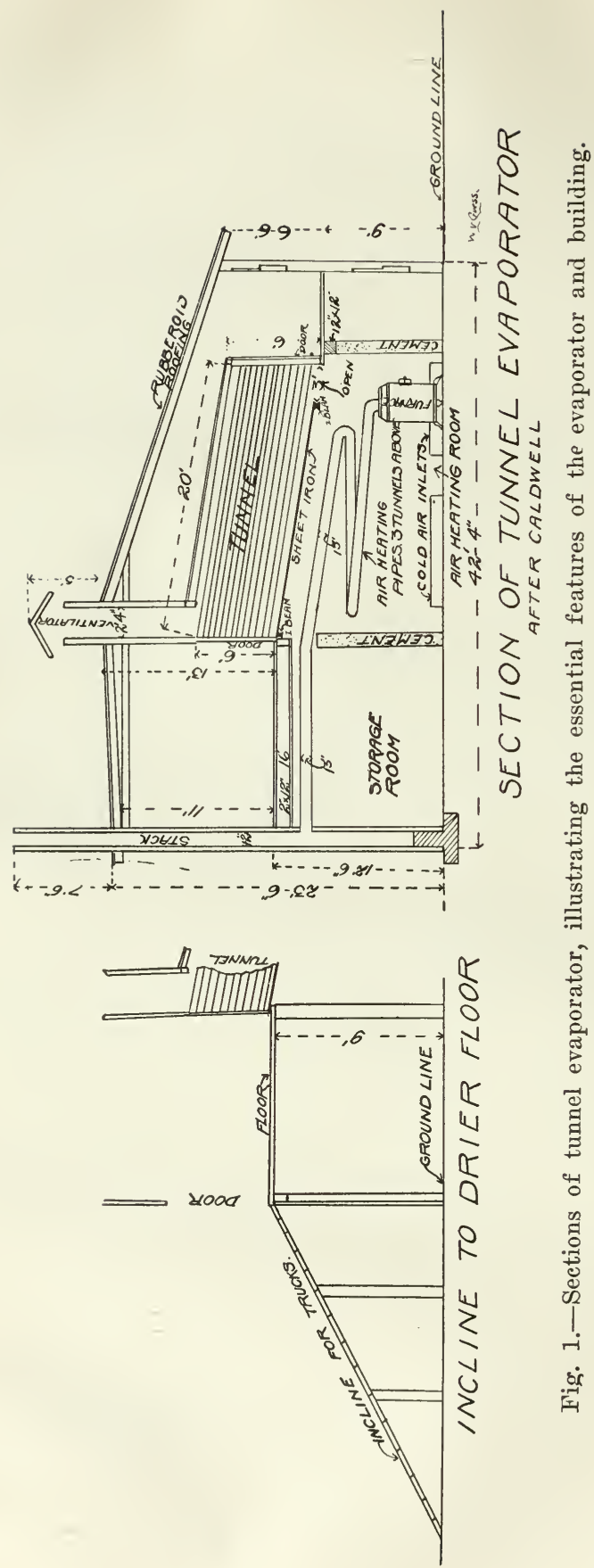
The trays of fruit enter the upper and cooler end of each tunnel on slides or runways and are taken from the lower and hotter end of the tunnel when dry; the tray entering the upper end displaces a tray of dry fruit at the lower end.

This evaporator is of moderate cost, is not difficult to operate, is efficient in its use of heat and gives a good dried product.

(a) General specifications of a tunnel evaporator:

(1) Six tunnels, $20^{\prime} \times 363$ I $^{\prime \prime} \times 6^{\prime}$.

(2) Slope of tunnels, $2^{\prime \prime}$ per $1^{\prime}$.

(3) Walls of tunnels of $2^{\prime \prime} \times 4^{\prime \prime}$ studs, covered with T. and G.

(4) Floors of tunnels of steet iron; ordinary heavy gauge galvanized iron will answer.

\section{STACK}

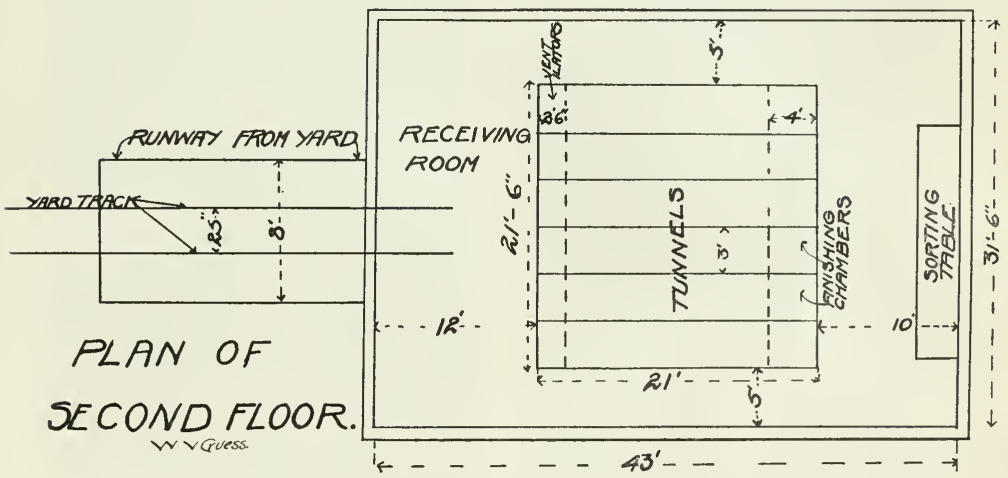

Fig. 2.-Plan of second floor, showing location of tunnels.

(5) Tunnels to be supported on $6^{\prime \prime}$ I beams which rest on brick or cement walls of the furnace room.

(6) Tray runways, $11 / 8^{\prime \prime} \times 11 / s^{\prime \prime}$. Six inches from center to center between first pair of runways at top of tunnel; $1 / 4$ " decrease in this distance between each two runways until $31 / 2$ " is reached for runways near bottom of tunnel. Telephone insulators may be added to runways to facilitate sliding of trays. (See fig. 3.)

(7) Ventilator, $30^{\prime \prime} \times 36^{\prime \prime}$, for each tunnel, and $16^{\prime}$ in height from top of tunnel, and equipped with damper, as shown in figure 5.

(8) Doors at each end of tunnel of beaver board or transite board on light frame. Doors to slide upward and to be balanced by window weights on pulleys above tunnels. (See fig. 3.)

(9) Opening 3' wide at lower end of each tunnel floor and fitted with sliding door, as shown in figure 5 .

(10) Finishing chamber equal to length of one tray and height of three tray runways at top of tunnel at lower end. Chamber has no floor. (See fig. 4.)

(11) Heating chamber 22' long, 10' wide, 12' high at one end and $9^{\prime}$ at the other. Walls of $8^{\prime \prime}$ concrete or of brick or tile. Roof of heating chamber is formed by floor of tunnels. Floor of earth or cement as desired. (See figs. 1 and 5.) 
(12) Four openings, $3^{\prime} \times 1 \frac{12^{\prime}}{}$ in walls of heating chamber $6^{\prime \prime}$ from ground. Fitted with adjustable sliding doors to regulate air intake. (See figs. 1 and 5.)

(13) Furnace $8^{\prime} \times 2 \frac{1}{2^{\prime}} \times 2^{\prime}$. Walls and floor of fire brick. Top of $1 / 2{ }^{\prime \prime}$ sheet iron arched. Furnace door to be flush with outer wall of furnace room. Other end of furnace to connect to $16^{\prime \prime}$ pipe. Furnace to be equipped with large rotary crude oil or stove distilate burner.

(14) $16^{\prime \prime}$ pipe reducing to $13^{\prime \prime}$ pipe to be arranged from furnace back and forth across heating chamber. Pipe to slope gently upward throughout to stack connection, but not to approach nearer than $30^{\prime \prime}$ to floor of tunnels. About 125 feet of pipe should be used. (See fig. 5 for general plan of piping.) Best to have pipe at least $48^{\prime \prime}$ below floor.

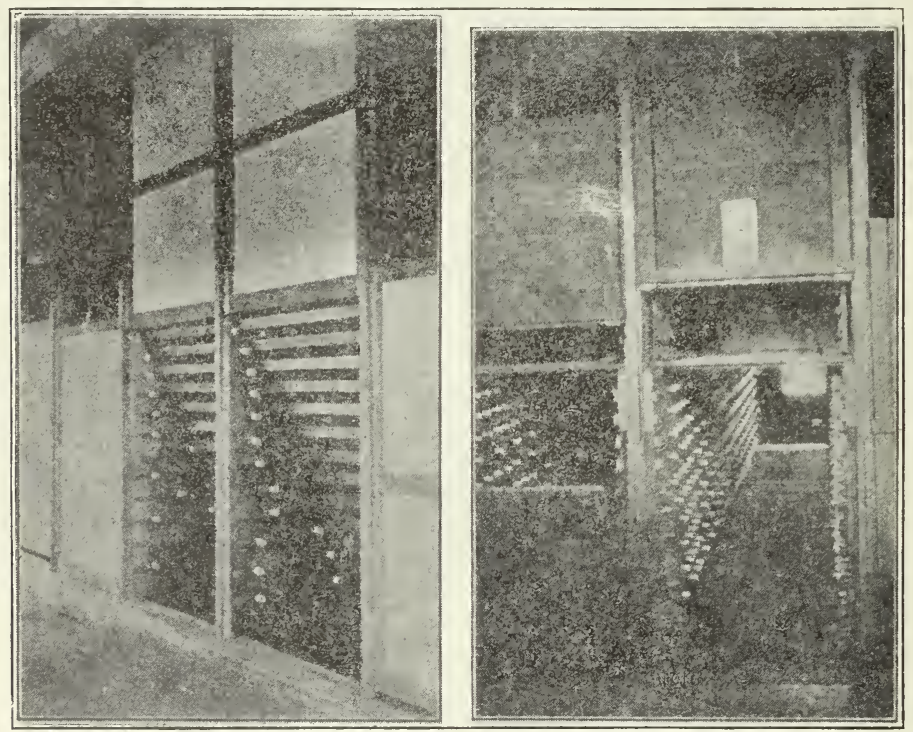

Fig. 3.-Lower end of tunnel, showing construction of sliding doors of beaver board and of tray runways. Note that trays are offset and that the upper trays extend farther than the lower. (After Bulletin 145, Oregon Agricultural Experiment Station, by Lewis, Brown and Barss.)

(15) Thermometers must be placed in tunnels at lower and upper ends; a recording thermometer at lower end of one tunnel is very useful.

(16) Sorting table, $15^{\prime} \times 3^{\prime}$, as shown in figure 2.

(17) Trays of $1 / 4$ " or $1 / 3$ " mesh hardware eloth between two frames of $7 / 8$ " by $1 \frac{1}{2}$ " spruce slats. Frames for $3634^{\prime \prime}$ tunnel to be $36^{\prime \prime} \times 48^{\prime \prime}$ or $36^{\prime \prime} \times 36^{\prime \prime}$ and braced by two $7 / 8$ " $\times 7 / 8$ " crosspieces. There should be about 100 trays for each tunnel to permit continuous operation of the evaporator.

(18) Building to be of barn construetion and of general dimensions shown in figures 9 and 10. To consist of two furnace rooms on ground floor; a receiving room or receiving porch about $32^{\prime} \times 12^{\prime}$; a sloping space $31^{\prime} 6^{\prime \prime}$ wide $\times 21^{\prime}$ long for tunnels, permitting an alleyway 5 ' wide at each side of tunnels; a room $10^{\prime} \times 31 \frac{1}{2} 2^{\prime}$ at lower end of tunnels for receiving trays from evaporator; roof of rubberoid roofing, galvanized iron, or shingles. 
(19) Alternative construction for building: Some evaporators are housed in galvanized corrugated sheet-iron buildings. This type of construction reduces the fire risk.

(b) Cost of Tunnel Evaporator: The cost will depend very largely upon the quality of materials used and upon how much of the construction is done by the owner. A seven-tunnel evaporator was built by L. J. Eddens of Dundee, Oregon, for $\$ 1300$ cash in 1916. It has a capacity of nine tons at each loading. This cost is exceptionally low because the owner did not add the value of his own labor to the cost of construction. This evaporator is described in Bulletin 145 of the Oregon Agricultural Experiment Station at Corvallis.

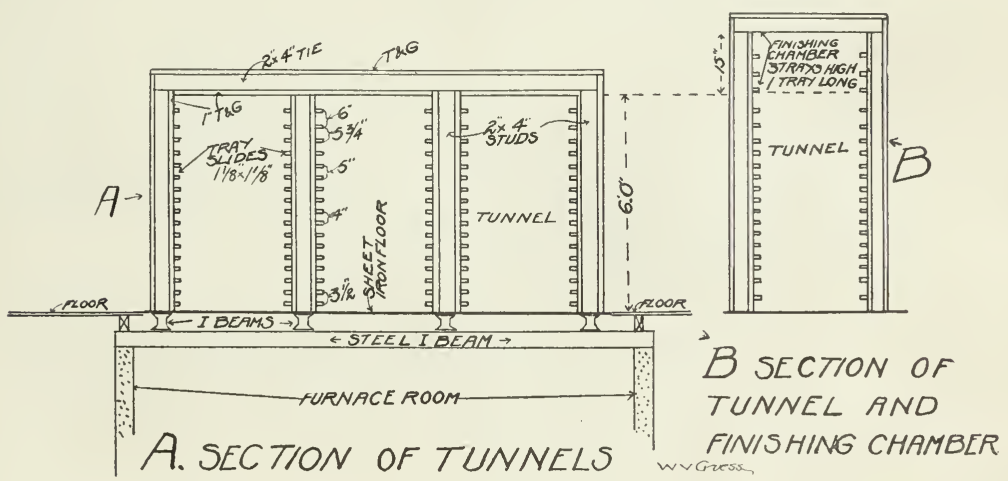

Fig. 4.-A, cross-section of tunnels; B, cross-section of tunnels, showing finishing chamber.

J. S. Caldwell estimates the cost of a nine-tunnel evaporator of first class construction at $\$ 3828$. This evaporator is described in Bulletin 148 of the Washington Agricultural Experiment Station, at Pullman.

Caldwell's estimates of costs are as follows:

1. Concrete work, $105 \mathrm{cu}$. yds., at $\$ 8$

2. Iron rods for reinforcements, $2000 \mathrm{lbs}$, at $6 \mathrm{c}$

3. Roofing, 3-ply asphalt, $3000 \mathrm{sq}$. ft., at $\$ 2.50$ per square

4. Rafters, $1500 \mathrm{ft} ., 2^{\prime \prime} \times 6^{\prime \prime}$, at $\$ 20$ per 1000

5. Sills and joists, $1600 \mathrm{ft} ., 6^{\prime \prime} \times 6^{\prime \prime}$, at $\$ 20$

6. Framing for ventilators, bins, and tunnels, $4800 \mathrm{ft}$. of $2^{\prime \prime} \times 4^{\prime \prime}$, at $\$ 20$ per 1000

7. Flooring, 5500 ft., at $\$ 28$ per 1000

8. Ship lap for sheathing roof, making bins and ventilator, $8000 \mathrm{ft}$. at $\$ 16$ per 1000 
9. Chimneys, conerete base and brick flues ................................................. $\quad 60.00$

10. Furnaces, three with fire brick lining, complete ..................................... $\quad 60.00$

11. Piping, 720 ft., 9-inch, at $10 \mathrm{c}$.......................................................... $\quad 72.00$

12. Runways for trays, $800 \mathrm{ft} ., 1^{\prime \prime} \times 7 / 8 "$, at $\$ 20$................................... $\quad 16.00$

13. Metal sheets for floor of tunnels, 475 sq. ft. at $\$ 4$ per square ............ $\quad 20.00$

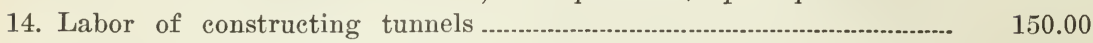

15. Twenty doors for tunnels, at $\$ 4$, ten outer doors at $\$ 4$..................... $\quad 120.00$

16. Twenty windows at $\$ 1.60$.................................................................... $\quad 35.20$

17. Lumber for paring tables, spreading tables, chutes, conveyors, and bleacher for apples, $1200 \mathrm{ft}$., at $\$ 28$ per 1000 ............................. $\quad 33.60$

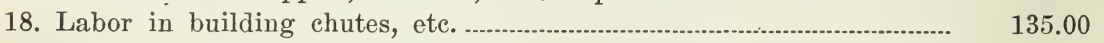

19. Master carpenter, at $\$ 5.50$; ordinary earpenter, at $\$ 4.50$ per day.

Carpenters' labor on floors, bins, ventilators, windows, etc........... $\quad 320.00$

20. Metal parts for conveyor, bleacher, and shafting and belting ........ $\quad 200.00$

21. Minor hardware, nails, hinges, ete. ........................................................ $\quad 80.00$

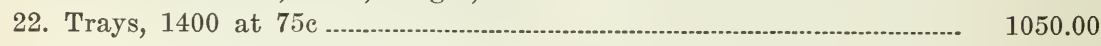

Total

For a prune evaporator for California, items 17, 18, and 20 would be omitted. This would reduce the total to $\$ 3460.20$. This evaporator would hold at one charge about $101 / 2$ tons of fruit.

A six-tunnel evaporator would, based on two-thirds of the above estimate for a nine-tunnel evaporator, cost about $\$ 2250$, although a six-tunnel evaporator would cost more than two-thirds as much as a nine-tunnel evaporator, because the latter does not require a building one-half larger than the six-tunnel type.

Probable $\$ 2500$ is a safe estimate of the cost of a six-tunnel prune evaporator. The evaporator building is very useful for storage of trays, lug boxes, and machinery during the slack season.

(c) Discussion of Oregon Tunnel Evaporator: Being built upon the unit system, a single-unit small evaporator of one to three tunnels may be built, and a large evaporator may be readily made by increasing the number of units. Where a small evaporator of three tunnels or less is built, it will often be possible to utilize an existing building to house the evaporator. A small evaporator of this type is fully described in Farmers' Bullein 984, a copy of which may be obtained free of charge from the United States Department of Agriculture, Washington, D. C.

The individual tunnels should be separated from each other to obtain the most satisfactory and uniform air circulation. The floor of the tunnel, except for the three-foot opening at the lower end, should be covered with sheet metal. The floor is omitted in some tunnels, but this construction results in improper circulation and in overheating of the lower trays. 


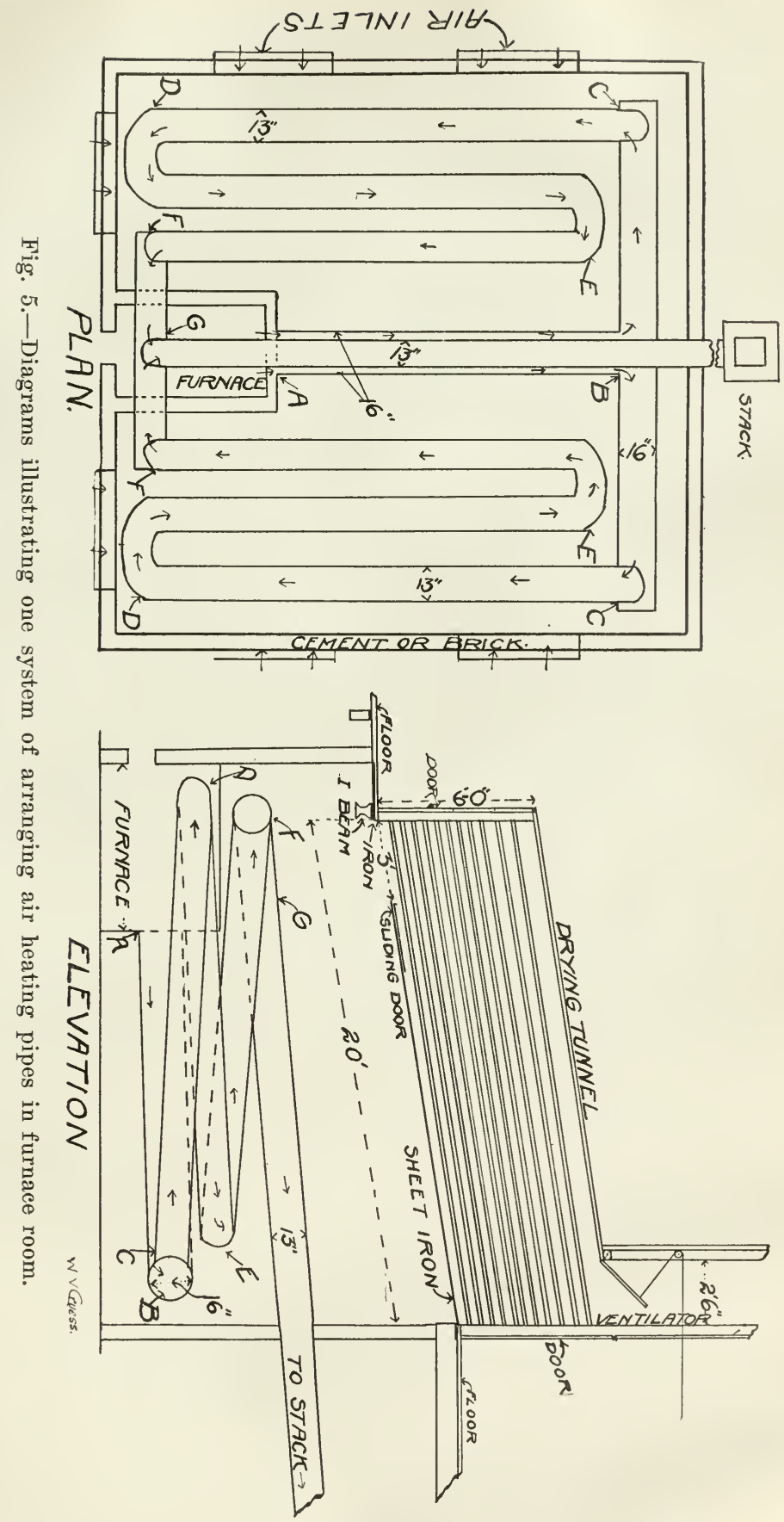


The tray runways may be seen in figure 3. If these runways are not smooth and perfectly straight it requires undue force to move the trays. Telephone insulators or small easters nailed to the runways facilitate sliding of the trays. A small cleat at the lower end of each runway will hold the last tray in place.

If the upper runways are farther apart than the lower, air circulation is made more uniform. For the same reason the upper trays should extend farther over the tunnel throat than the lower trays. (See fig. 3.)

The ventilator is a very important feature of the evaporator because upon its operation depends the air flow through the tunnel. It should be tall enough to give a good draft; a velocity of air flow of about 600 feet or more per minute is desirable. The ventilator extends across the upper end of all of the tunnels but should have partitions separating it into a flue for each tunnel. The ventilator should be at least 30 inches wide and 15 to 20 feet tall to give satisfactory results. Each flue of the ventilator should be fitted with a damper that ean be easily regulated, as shown in figure 5.

The air heating system must be large enough to heat a large volume of air to $150^{\circ}$ to $160^{\circ} \mathrm{F}$. For three tunnels it will be about 10 feet by 22 feet. If it is much smaller than the dimensions given in the specifications it will be unsatisfactory. The heating room should be as long as the tunnels for the best results. The furnace should be located below the lower ends of the tumnels in order that the heat radiated from the furnace will be fully utilized.

The furnace room should be high; at least nine feet at the lower end and twelve feet at the upper end of the tunnels. This permits the use of sufficient heating pipe and causes the air to be thoroughly mixed and of uniform temperature before it enters the tunnels.

Fire-proof construction for the fire pit, as given in the specifications, is essential. Cement is preferable to corrugated sheet metal because the radiation losses are less and cement or brick walls act similarly to the walls of a bake-oven in stabilizing the temperature and in causing the air to be more uniformly mixed. Cement walls in other words act as a reservoir of heat.

The air-heating pipes must give enough radiating surface to impart most of the heat from the burning fuel to the air. About 150 feet of 13-inch pipe, or 200 feet of 9-inch pipe, is desirable for three tunnels. It is led back and forth across the chamber and across ends of the chamber by ' $\mathrm{T}$ unions. The pipe must have a gentle upward slope from the furnace to the smokestack. All joints must be smoke-tight; 
otherwise smoke and bad odors will enter the tunnel and spoil the fruit. The topmost pipe should be three feet or more below the tunnel floor to permit proper mixing of the heated air. Figure 5 illustrates a heating chamber for four tunnels.

The fresh-air inlets must be placed near the floor of the heating chamber in order that the incoming air will flow over the heating pipes. Hollow tiles have been used with good results. The inlets must be fitted with sliding doors to permit regulation of the air flow.

The furnace should be large enough to burn completely the crude oil or other fuel used. The furnace given in the specifications will take care of a large rotary or forced draft oil-burner of such types as the Ray or Johnson burners. A forced draft oil-burner is very satisfactory, although wood or coal may also be used. If desired, the top of furnace may be covered with brick. The walls and floor of the furnace are best made of fire brick, although heavy iron has been used successfully by E. B. Stone of San Jose. Hop kiln stoves are often used in Oregon, but are said to be short-lived. Commercially built, ready-to-install furnaces may be bought from certain California firms. Most of these are very satisfactory.

The trays are of wire screen of $1 / 3$ or $1 / 4$-inch mesh; $1 / 2$-inch mesh may allow small prunes to drop through. Wooden trays can not be used advantageously. Wooden trays impede air circulation, result in a large loss of heat used in heating the wood, and permit drying on one side only of the fruit. The objections are made to wire screen trays that they are expensive and that the screen marks the fruit. Most of the marks, however, disappear during processing and packing. The increased capacity and saving in fuel offset any extra cost of screen trays.

A tray $3^{\prime} \times 4^{\prime}$ is as large as one man can handle; a $3^{\prime} \times 3^{\prime}$ tray is more convenient, but to facilitate the transfer of fruit from $8^{\prime} \times 3^{\prime}$ dry-yard trays, the $3^{\prime} \times 4^{\prime}$ evaporator tray will be found useful. Two of these equal one wooden tray.

Construction of a tray: Make a frame of $7 / 8^{\prime \prime} \times 11 / 2^{\prime \prime}$ spruce, $4^{\prime}$ long and $3^{\prime}$ wide. Cut a piece of galvanized wire screen $\left(1 / 4^{\prime \prime}\right.$ or $1 / 3^{\prime \prime}$ mesh) one inch larger each way than the frame. Turn back the edges of the screen one inch to give a firmer hold for nailing. Tack it to the frame stretching it tightly. Then over the screen and first frame nail a second frame of the same size and construction as the first. Nail two $7 / 8^{\prime \prime} \times 7 / 8^{\prime \prime}$ strips across the tray on one side only and one foot from each end to give rigidity. The tray is reversible and should be reversed occasionally to prevent sagging of the screen. The frame will be about 2 inches thick and $11 / 2$ inches wide. 
(d) Operation of the Evaporator: To operate the tunnel evaporator, proceed as follows: Start the furnace; open the air intakes and ventilator dampers. Heat the tunnels to $150^{\circ} \mathrm{F}$. at lower end. Place fresh or wet fruit on the trays, about 25 pounds to a $3^{\prime} \times 4^{\prime}$ tray, and fill the tunnel by sliding trays in from upper end. Regulate heat and draft so that a temperature of $150^{\circ} \mathrm{F}$. is maintained at the lower end of the tunnels until the prunes at this end are dry enough. Do not dry the prunes too much. Prunes in the evaporator are much softer than prunes of the same moisture content on trays in the sun because of the higher temperature in the evaporator. To make a fair comparison, remove a few prunes and chill them in the air for ten or fifteen minutes and note texture of the flesh.

When the trays of prunes at lower end of tunnel are sufficiently dry, remove them and enter the same number of trays at the upper end of the evaporator.

The trays must be so arranged that they are offset over the throat of the tunnel, as shown in figure 3. This permits even circulation of the air.

2. Air-Blast Evaporator.-The evaporator to be described consists essentially of two horizontal tunnels placed side by side and resting on the ground; a fan and air heating system at one end of tunnels and ventilator at other end; and of two sets of car tracks upon which loaded cars of trays are placed. The specifications are as follows:

(a) General Specifications of Air-Blast Evaporator:

(1) Two tunnels, $36^{\prime} \times 7^{\prime} \times 7^{\prime}$, resting on ground and side by side. (See fig. 6.) A slope of $1 / 2$ " or $3 / 4$ " per foot from entrance to fan end of drier will facilitate handling of loaded cars.

(2) Two sets of ordinary dry-yard tracks in each tunnel, $36^{\prime}$ long inside tunnel and connecting to transfer tracks, as shown in figure 6 .

(3) Transfer track, $15^{\prime}$ beyond end of tunnels and at right angle to turnels. (See fig. 10.)

(4) Transfer track connecting tracks inside tunnels to yard tracks parallel to tunnel. This transfer track located $36^{\prime}$ from entrance end of tunnel and $11^{\prime}$ in front of fan. (See fig. 6.)

(5) Folding doors closing ends of tunnels at entrance end of tunnels; two doors to each tunnel; each door $3 \frac{1}{2}$ ' wide and each pair of doors meeting at center of each tunnel. (See fig. 6.)

(6) Sliding door $10^{\prime}$ long, $7^{\prime}$ high at side of each tunnel at fan end to permit removal of carload of $8^{\prime} \times 3^{\prime}$ trays crosswise. (See fig. 6.)

(7) Fan, $6^{\prime}$ dise fan to deliver 35,000 cubic feet of air per minute. 275 r.p.m.

(8) Motor for fan, 8 h.p.

(9) Air heater : 3000 feet or more of 1" black pipe built into vertical coils and connected to 40 h.p. boiler and return steam traps. These coils can be bought ready made or built as shown in figure 9 . 


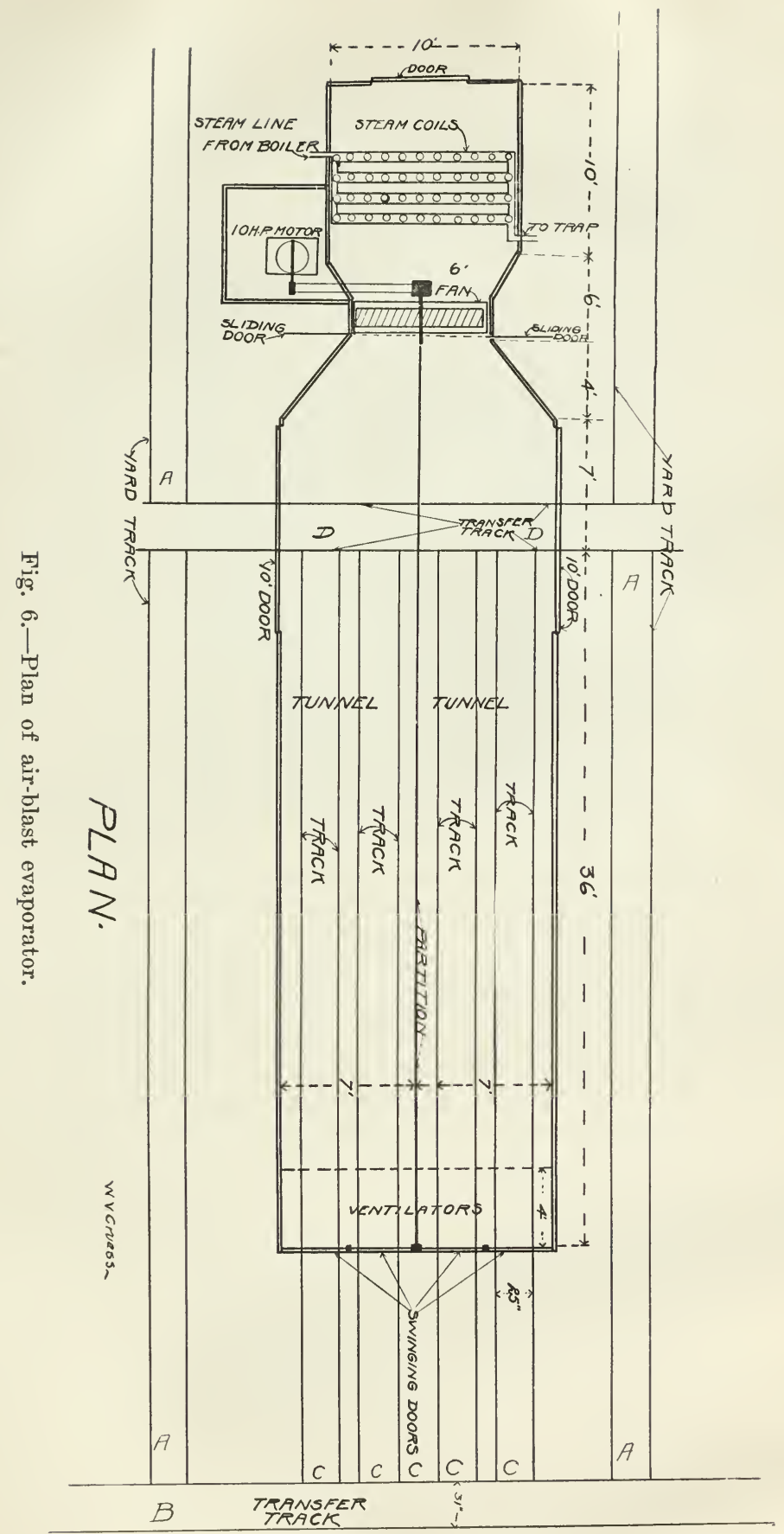




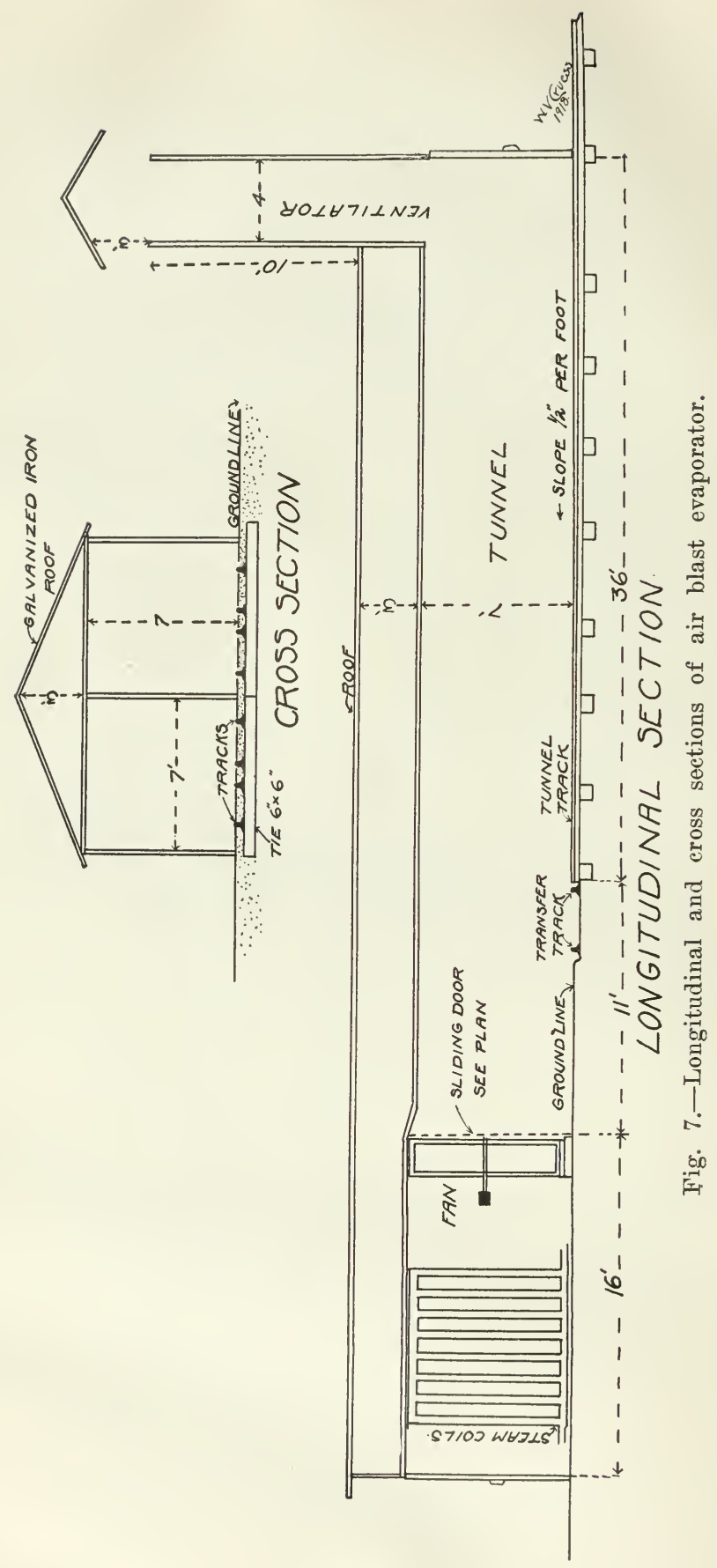


(10) Alternative form of air heater: Furnace room, 15' wide, 20' long, 10' high, of sheet metal or concrete, tile or brick; an $8^{\prime} \times 2 \frac{1}{1} 2^{\prime} \times 2^{\prime}$ fire-brick furnace connected to a system of 300 or more feet of $12^{\prime \prime}$ to $16^{\prime \prime}$ radiating pipe and smokestack, as illustrated in figure 5, and equipped with large rotary oil-burner. Furnace room to be suitably connected by sheet metal to fan room. Fan room to be of sheet metal or other fire-proof material to reduce fire risk.

(11) Roof of evaporator: Of rubberoid roofing, corrugated sheet iron, or shingles.

(12) Trays: Ordinary $8^{\prime} \times 3^{\prime}$ dry-yard trays may be used, but better results will be obtained with $1 / 4^{\prime \prime}$ mesh screen trays, $3^{\prime} \times 4^{\prime}$ in size with open ends for passage of air. About 1000 such trays would be needed.

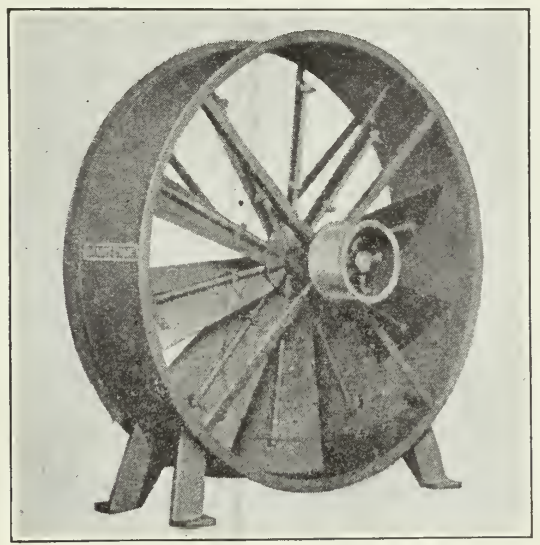

Fig. 8.-Dise fan. (Courtesy of B. F. Sturtevant Company.)

(b) Cost of Air-Blast Evaporator: A California firm gave an estimate of $\$ 1550$ for cost of fan, steam coils, trap, and connections to boiler. The alternative form of air heater described in specification 10 would be cheaper. A 40 h.p. boiler will cost, installed complete and ready to operate, not less than $\$ 1000$. The tunnels, tracks, and building should be built for $\$ 1000$. The motor will cost about $\$ 200$ and incidental equipment should not exceed $\$ 250$. On the basis of these rough cost estimates, the evaporator would cost about $\$ 4000$.

The West Side Association evaporator was built several years ago for about $\$ 1500$ without the boiler. At that time the fan and coils cost only about $\$ 850$. The association had installed a boiler several years before the evaporator was built and has used it for heating water for dipping prunes. No record of cost of the boiler could be given. Boiler, fans, pipe, and lumber are at present abnormally high in price. In normal times, the evaporator should easily be built and equipped for $\$ 3000$, especially if the alternative form of air heater is used. 
(c) Discussion of Air-Blast Evaporator: The drying chambers are specified horizontal. If they are built with a gentle slope from the ventilator end toward the fan end, the cars of loaded trays may be moved much more easily and it is probable that the air circulation will be improved. The American Products Company of San Francisco has found that sloping tunnels are much to be preferred.

The chambers are wide enough to accommodate two lines each of loaded cars with one foot of free space to allow for irregularities in stacking the trays, but are not so wide as to leave large channels between the trucks or between the trucks and walls. If the air tends to follow these channels, baffles may be placed to deflect air over trays.

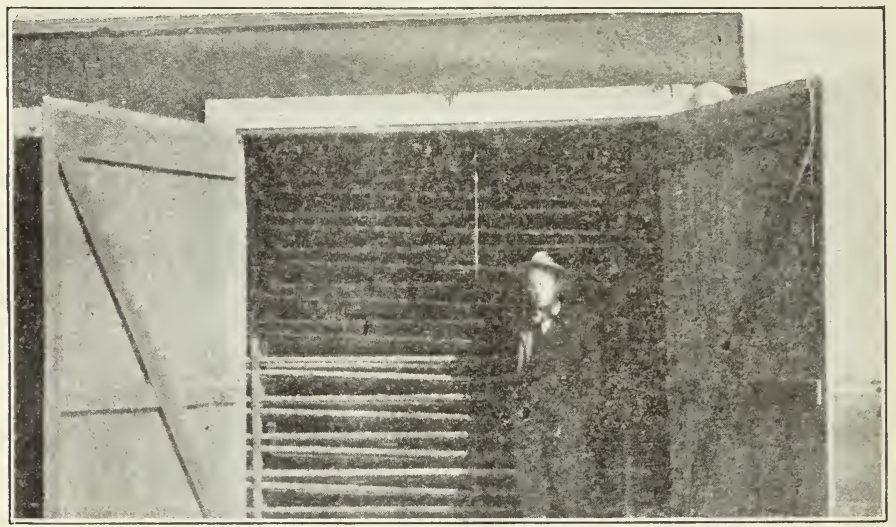

Fig. 9.-Air heating steam coils of Yolo Orchard Company's evaporator, Woodland. Note downward slope of pipes to facilitate drainage.

Each tunnel has two lines of track. These tracks are connected to yard tracks outside the dryer and to a transfer track at dryer exit, as shown in figure 6 .

The walls and ceiling of the tunnels should be as nearly air-tight as possible, although the partition between the two tunnels need not be so.

The ventilator should equal or exceed in area of cross-section the area of cross-section of the fan in order that the air flow shall not be hindered. The current of air from the fan should flow in the same direction as the prevailing winds. In some evaporators the ends of the tunnels opposite the fan are left open and the spent air is allowed to escape without the use of a ventilator. Such a plan is said by some engineers to give good results and is much better than the use of too small a ventilator. A good ventilator assists the fan by increasing the air flow. 
Air circulation in the evaporator is obtained by use of a fan. A dise fan is recommended in preference to a pressure blower because the dise fan requires very much less power for operation and is much cheaper than the pressure blower type. The disc fan delivers a large volume of air at low pressure and is not satisfactory where very heavy resistance opposes the air flow, but gives very good results with the

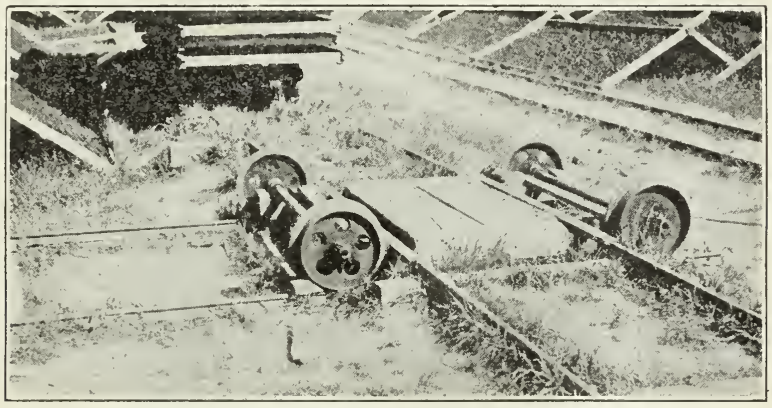

Fig. 10.-Transfer car and track used by West Side evaporator.

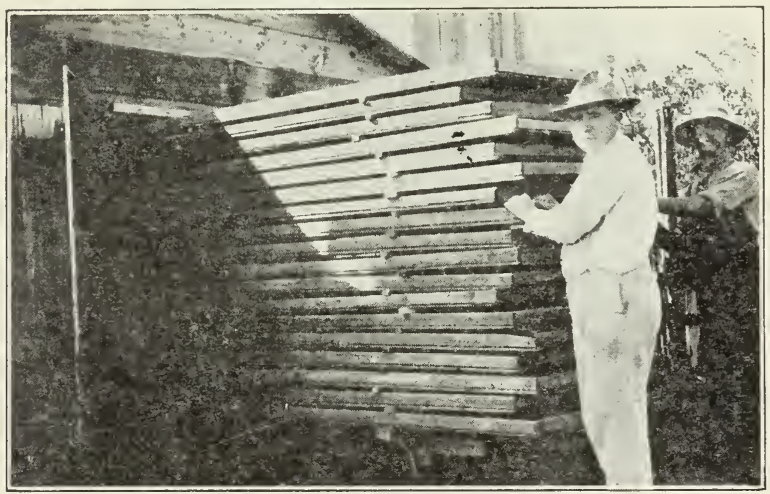

Fig. 11.-Illustrating method of stacking wooden trays on evaporator truck. Note that the trays are offset and have $7 / 8$ " pieces between them to permit passage of air.

style of dryer under discussion. The fan may be bought ready to connect or may be made to order by a sheet-metal shop. A six-foot disc fan will require an 8 h.p. motor or engine of the same power. A steam engine may be used and the exhaust steam may be passed through the coils to heat the air. This system is used in the West Side evaporator at Cupertino. If an electric motor is used it is best to protect it against the high temperature of the air passing through the fan. Fig. 6 illustrates a small closed room for the motor. 
The fan draws the outside air through a heating system. In the specifications a heater made of at least 3000 feet of black iron pipe connected to a 40 h.p. boiler is recommended. This heater may be obtained from various manufacturers or may be built by a steam fitter and assembled at the plant; the manufactured heater will usually be the more satisfactory. Figure 9 illustrates a home-made air heating coil.

Steam boilers and steam coils are very expensive and their use requires the employment of a licensed steam engineer. For these

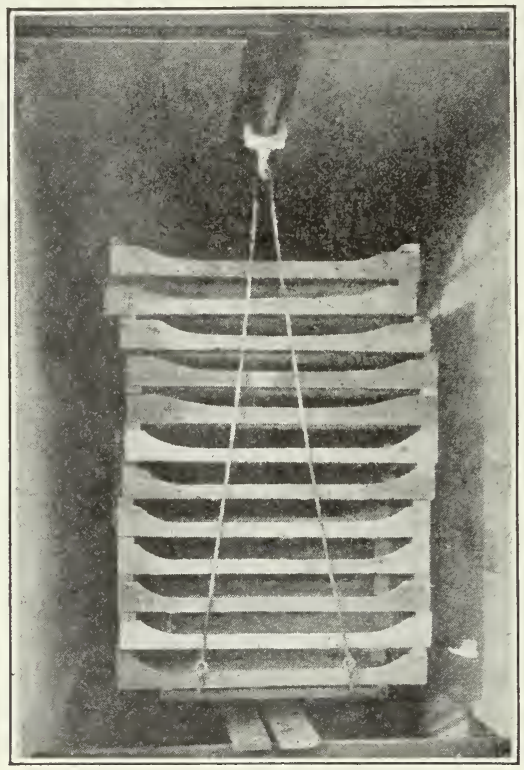

Fig. 12.-Wire screen trays used in Heilmann and O'Brien Evaporator, Marysville, California. Note construction of trays to permit passage of air. Also note arrangement of overhead conveyor. There is too much space between trays and walls.

reasons, many builders of evaporators install a furnace and heating pipes similar to the heating system previously described for the Oregon tunnel evaporator. The furnace must be large and at least 300 feet of 12-inch or larger pipe must be installed. Specification 10, page 17, fully describes such an air heater. Large drums have been used instead of pipe but do not give sufficient radiating surface and result in a very large loss of heat through the smoke stack.

The total area of the air intakes into the heating chamber should be as large as a cross-section of the fan. They must be fitted with sliding doors by which the air flow may be regulated. 
A self-registering thermometer is very useful. Other good thermometers should be installed at entrance and exit of the tunnels.

Wooden trays may be used if stacked on the trucks so that air may pass between them freely. The evaporator will hold about 320 such trays. (See fig. 11.) Wire sereen trays $3^{\prime} \times 4^{\prime}$ in size may be made as follows: Make sides of $2^{\prime \prime} \times 1^{\prime \prime}$ material, making height of sides $2^{\prime \prime}$. Make ends of $1^{\prime \prime} \times 2^{\prime \prime}$, but place the pieces flat. This makes ends $1^{\prime \prime}$ lower than sides. Nail screen to bottom of the frame and cover with $1 / 4^{\prime \prime}$ strips. At 18 inches from each end of the tray nail a $7 / 8 " \times 7 / 8$ " strip above the screen to prevent sagging and to

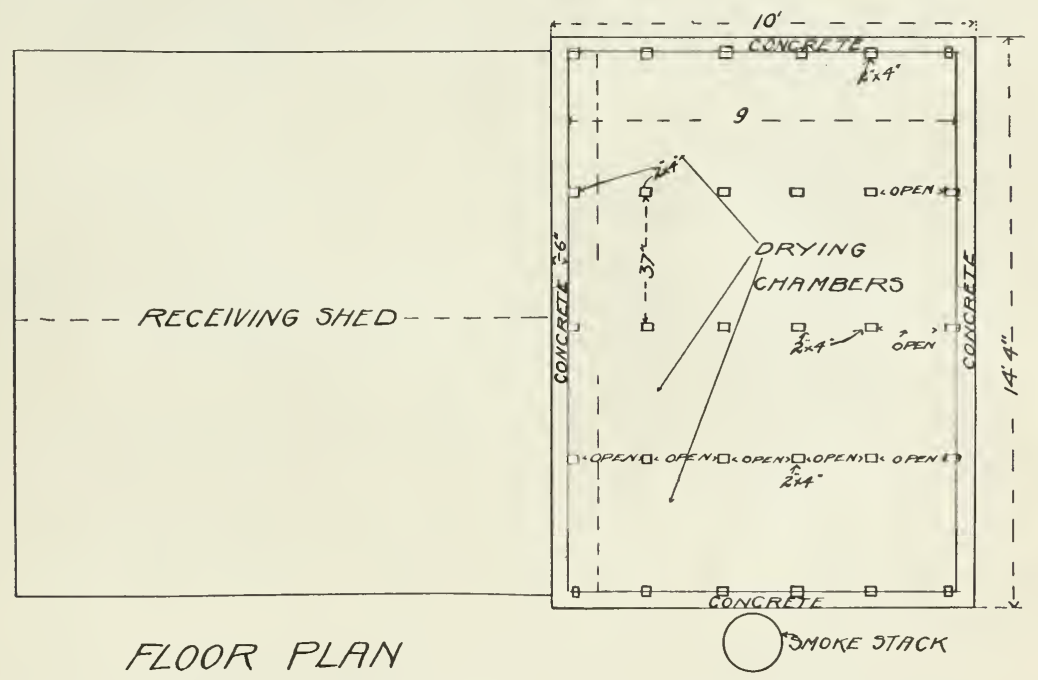

Fig. 13.-Floor plan of Young evaporator. Receiving shed is not drawn to scale.

support the frame. These trays are to be stacked lengthwise on the tunnel trucks to permit free passage of air from the fan. The evaporator will hold about 800 such trays. Figure 12 illustrates another style of tray that may be used.

(d) Operation of Air-Blast Evaporator: The path travelled by the trays from the dry-yard through the evaporator ean be seen best by referring to figure 6. A yard truck is loaded with trays, as shown in figure 11. The truck is then brought on yard track $\mathrm{A}$ to transfer track B. The ear is transferred to track $\mathrm{B}$ and by means of $\mathrm{B}$ to one of the tunnel tracks C. The ear is then pushed into the drying chamber on track $\mathrm{C}$, the long diameter of the trays being parallel to the tracks C. When the tunnels are filled with cars the fan and steam coils are started. The temperature of the air delivered to the evaporator is regulated to $150^{\circ} \mathrm{F}$. 
When the fruit on the trays at the fan end of the evaporator is dry the car of trays containing this fruit is moved to the transfer track D. The carload of dry trays is then removed from the drying tunnel to one of the yard tracks A. The trays are taken crosswise from the evaporator; i.e., with their greater diameter still parallel to the tunnels. As one car is removed at D another carload of fresh fruit is entered at $\mathrm{C}$ and the line of cars in the tunnel is moved ahead to make room for the fresh fruit.

3. The Young Evaporator.-This is a small, inexpensive and satisfactory evaporator used in Napa County. The specifications below are those of the evaporator in the dry yard of Fred Haas, Yountville. It is a simple form of stack evaporator.

\section{(a) General Specifications of Young Evaporator:}

(1) Four drying compartments, $9^{\prime}$ long $\times 7^{\prime}$ high $\times 37^{\prime \prime}$ wide above a fire pit. Compartments open above pit and to ventilator.

(2) Each compartment equipped with 15 horizontal tray runways of $2^{\prime \prime} \times 2$ " material; runways $9^{\prime}$ long and nailed to $2^{\prime \prime} \times 4$ " studding.

(3) Partitions between compartments open except for tray runways.

(4) One folding door, $7^{\prime} \times 38^{\prime \prime}$ for each compartment.

(5) Outer walls of dryer of $1^{\prime \prime} \times 12^{\prime \prime}$ material surfaced one side, double, with $3^{\prime \prime}$ sawdust-filled space between.

(6) Roof of lean-to construction, lower side at height of top of drying compartments, higher side about 4 feet above top of compartments.

(7) Ventilator, $2^{\prime} \times 3^{\prime}$ and $3^{\prime}$ high in center of roof. (Should be about $10^{\prime}$ high.)

(8) Fire pit $14^{\prime}$ long $\times 9^{\prime}$ wide, $2^{\prime}$ below ground line and $4^{\prime}$ above. Walls of $6^{\prime \prime}$ concrete. Several $1^{\prime} \times 1^{\prime}$ openings at ground line for admission of air. Would be better if air were admitted at bottom of pit instead of at ground line.

(9) Furnace, 4' long $\times 3^{\prime}$ wide $\times 2$ ' high inside. Lined with fire brick. Furnace door about $8^{\prime \prime} \times 12^{\prime \prime}$. Excavation and steps leading from ground level to furnace floor level.

(10) Burner, larger stove distillate type. Fed from tank above by gravity.

(11) Air heating pipes: One $16^{\prime \prime}$ pipe connecting to furnace at one end of chamber and to 20" drum at other end. This 20" drum in turn connects to two $9^{\prime \prime}$ pipes which return to the furnace end of room. At the furnace end of room these two pipes connect by vertical elbows to two 9 " pipes which return to opposite end of pit. They are here joined by a $\mathrm{T}$ joint to a $9^{\prime \prime}$ pipe returning above center of pit to the smokestack. There are in all one $16^{\prime \prime}$ pipe about $8^{\prime}$ long; one $20^{\prime \prime}$ drum, about $81 / 2^{\prime}$ long; and five lengths of $9^{\prime \prime}$ pipe, each about $13^{\prime}$ long. One end of each $9^{\prime \prime}$ pipe projects through the cement wall and is covered with a soot cap to facilitate cleaning.

(12) Trays: Ordinary $8^{\prime} \times 3^{\prime}$ dry-yard trays are used but $4^{\prime} \times 3^{\prime}$ sereen trays of the form described for the Oregon tunnel evaporator would be much better. 


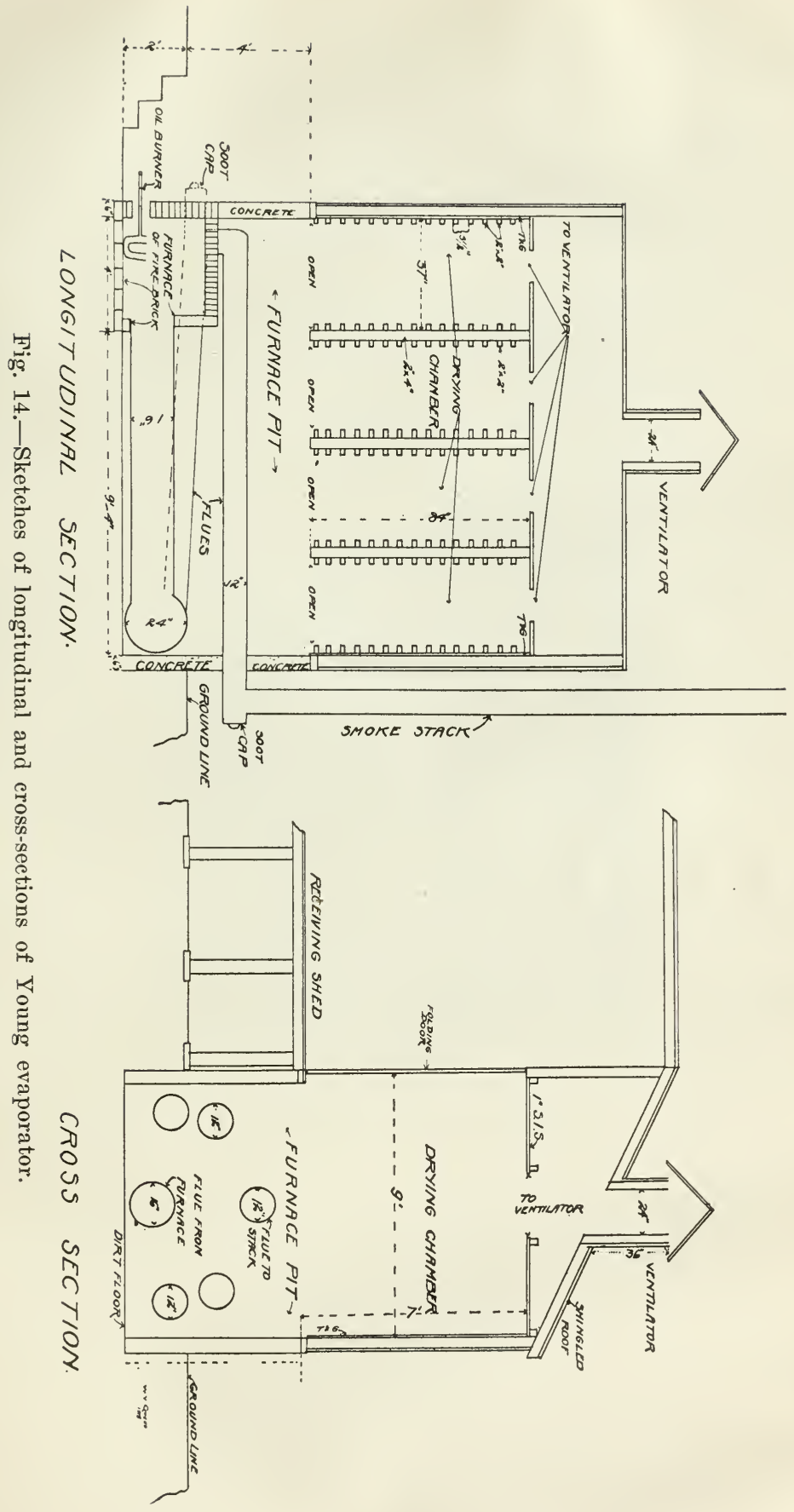


(b) Cost of Young Evaporator: The above evaporator without trays can probably be built for $\$ 500$ or less. The receiving shed is not included. Mr. Fred Haas of Yountville can give information relative to costs.

(c) Discussion of Young Evaporator: This evaporator would be improved if the capacity of the furnace were increased and if wire screen trays were used instead of the ordinary wooden dry-yard tray.

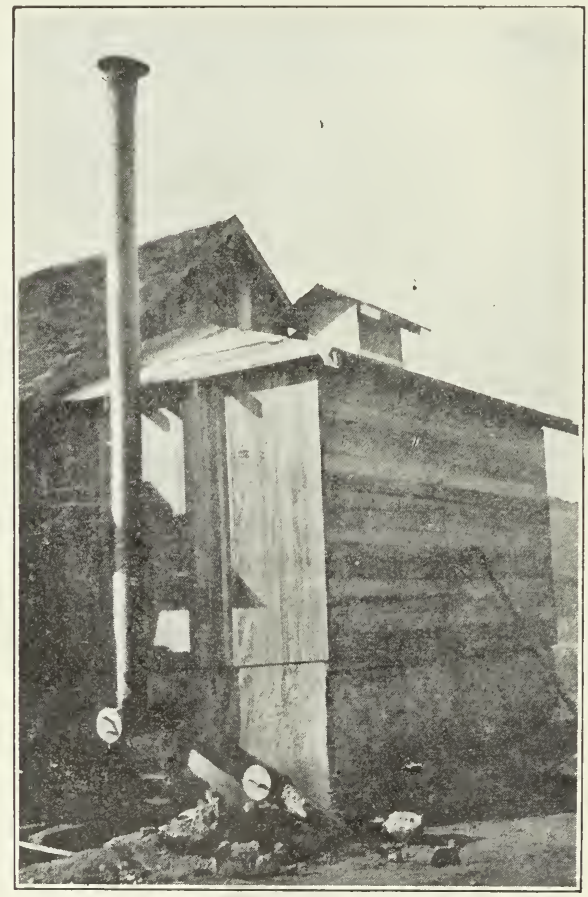

Fig. 15.-View of Young evaporator. The small box-like structure resting on the cement walls is the evaporator. The large building is the receiving shed.

The capacity of the evaporator is sixty $8^{\prime} \times 3^{\prime}$ trays of fruit per charge. If two-thirds dry when it enters the evaporator, the fruit will dry in about twelve hours. Mr. Haas was able to dry two charges of rain-damaged fruit per twenty-four hours and during the season handled about 100 tons of prunes on dry basis. The prunes were in some cases sulfured after the rains to prevent moulding and fermentation until they could be artificially evaporated.

An evaporator similar to the above is located in the Fisher dryyard at Union Station, Napa County. This dryer is equipped with 
two car tracks and holds four loaded cars of $8^{\prime} \times 3^{\prime}$ trays at each charge. It is said to have given good results. Both evaporators were installed by the Young Hardware Company of Napa.

(d) Operation of Young Evaporator: The furnace is first started and the dryer heated to $140^{\circ}$ to $150^{\circ} \mathrm{F}$. The trays of fruit are placed in the compartments by sliding them in on the tray runways. If wooden trays are used, drying is hastened and made more uniform by stirring the fruit occasionally. As the fruit becomes dry the trays are removed and are replaced by fresh trays. Two men are needed to handle $8^{\prime} \times 3^{\prime}$ trays.

A piece of sheet metal about $4^{\prime}$ wide and $14^{\prime}$ long is hung above the radiating pipes to distribute the heat evenly.

About thirty gallons of stove distillate is used per twenty-four hours.

\section{Other Evaporators.-}

(a) Kiln Evaporator: This evaporator is used in California chiefly for drying hops, but is used occasionally for apple drying. It is the most common form of apple evaporator in New York. It may be built as a single evaporator or as a battery of several evaporators.

It is built in two stories. The upper story houses the drying floor. This floor is usually $20^{\prime} \times 20^{\prime}$ and is made of narrow wooden strips with $1 / 4^{\prime \prime}$ or $3 / 8$ " space between them. The spaces permit the passage of air. Over the drying floor is a steep four-sided roof which has at its apex a large ventilator for the escape of the hot air. The prepared fruit or vegetables are spread on the drying floor and turned by a fork or shovel during drying. The lower floor contains the heating system. This consists of a wood- or oil-burning furnace from which is led a series of several turns of heating flues or pipes. These flues are usually joined at the furnace by a $\mathrm{T}$ and may be led around beneath the drying floor several times.

Drying is accomplished by the hot air rising from the hot flues through the spaces in the drying floor. The air is carried off by the ventilator in the roof.

Caldwell* places the cost of a four-kiln evaporator with wooden building at about $\$ 2500$. For a complete description of this type of evaporator see Farmers' Bulletin 903, United States Department of Agriculture. This style of evaporator is not well adapted to prune drying, as there is a tendency for the product to mold because of the slow drying; the control of temperature during drying is not satisfactory, and the fruit is mashed and broken during turning. It is

\footnotetext{
* Bulletin 148, University of Washington Agricultural Experiment Station.
} 


\section{6}

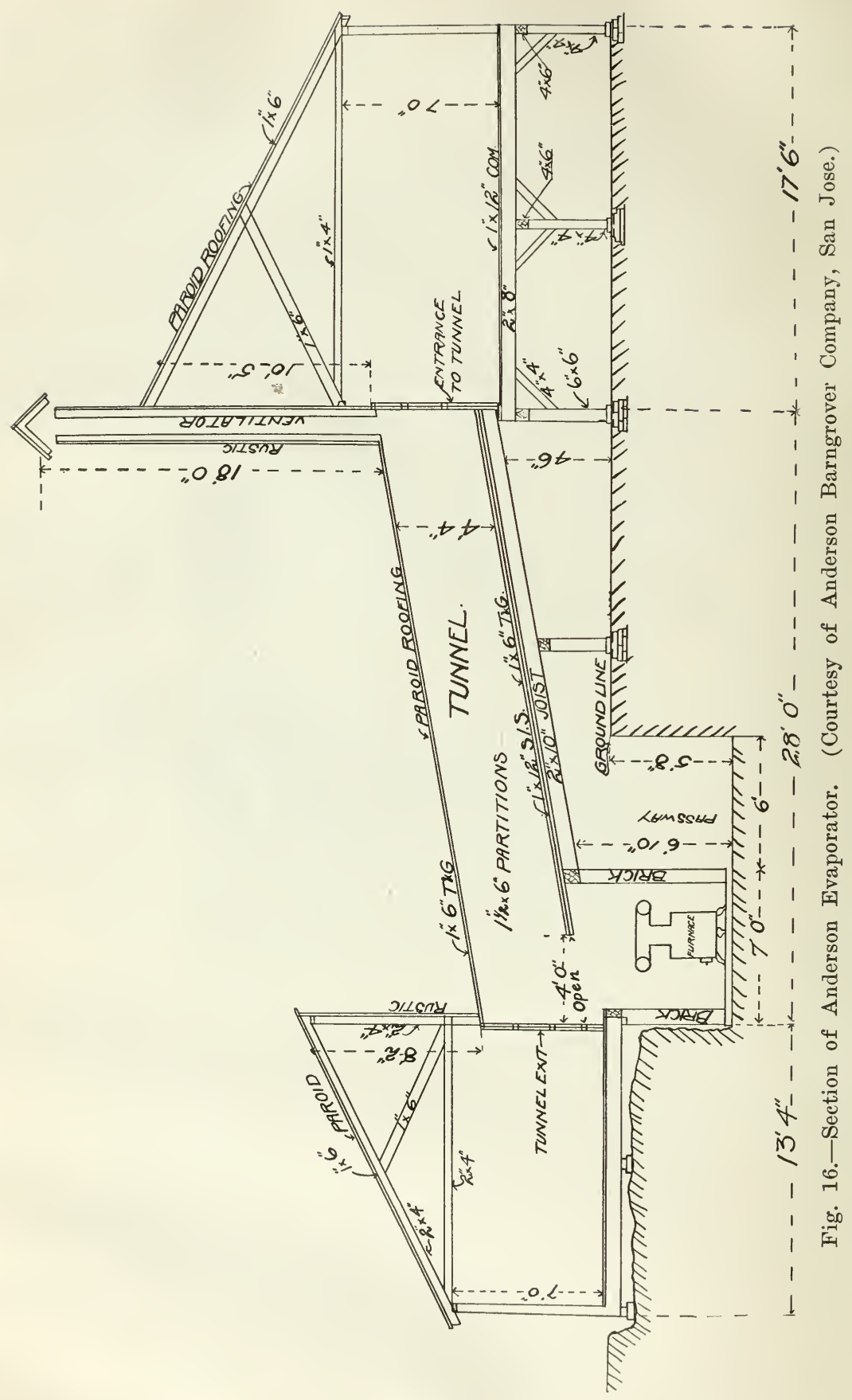


not recommended for prune drying, but where already installed for other purposes could be used in an emergency.

(b) Watsonville Stack Evaporator: This type of evaporator is used commonly in California for apple drying. The heating system is the same as for the kiln and tunnel evaporators. The drying cabinets or "stacks" are on the second floor. The drying takes place on trays which slide into a drying chamber situated directly above the heating flues. The bottom of the stack is open; the top consists of an inverted hopper which ends in a tall ventilator. According to information furnished by Mr. Henry Washburn, Farm Advisor, this style

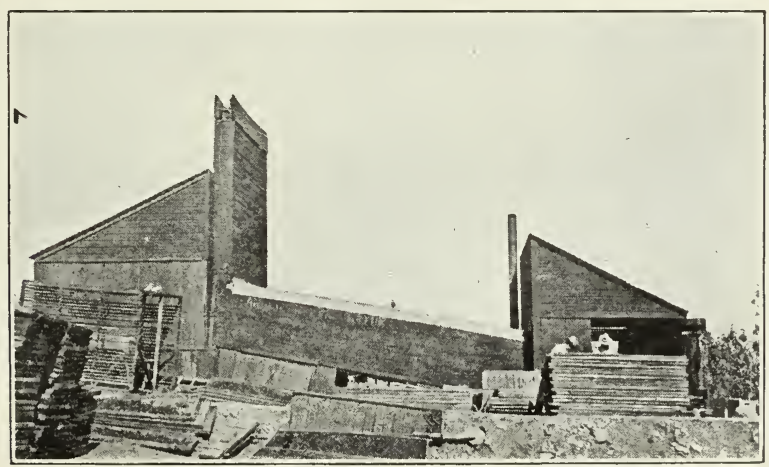

Fig. 17.-Anderson Barngrover evaporator on Mr. Husted's place near Saratoga. Note that evaporator is placed on side hill.

of evaporator can be built for $\$ 2500$ to $\$ 3500$ per unit. Each unit will produce from $1 / 2$ to $3 / 4$ ton of dried apples per day or will take about seven tons of fresh apples per day. Mr. Washburn can furnish specifications for this evaporator and the names of builders. The evaporator is inefficient in use of heat. It has no satisfactory temperature control and often rises to too high a temperature.

(c) The Anderson Evaporator: This is a form of tunnel evaporator found in a number of dry-yards in the Santa Clara Valley. It is used with the ordinary $8^{\prime} \times 3^{\prime}$ wooden tray.

Figures 16 and 17 will give an idea of its construction. As originally installed, it had very inadequate heating and ventilating capacity. Several were used during the past season, but none with entire satisfaction. Mr. C. B. Husted, near Saratoga, installed stovedistillate burners in the furnaces and then obtained fair results, in finishing prunes that were almost dry when the rain came. His evaporator is shown in figure 17. 
E. B. Stone has installed the most satisfactory improvement seen for this evaporator. He has built a furnace about 8 feet from the evaporator. It is in a pit about $5^{\prime}$ deep $\times 4^{\prime}$ wide. The furnace is of iron, is $8^{\prime} \times 12^{\prime \prime}$ and has $2^{\prime \prime}$ ribs. It connects to several long turns of $12^{\prime \prime}$ pipe which pass beneath the throats of the tunnels. The furnace is enclosed in an arched fire-proof chamber. The radiating pipes, $12^{\prime}$ long $\times 12^{\prime \prime}$ in diameter, are beneath the lower ends of tunnels in a cement pit about $5^{\prime}$ deep and $4^{\prime}$ wide. Air is blown over the furnace and pipes by a No. 2 Sturtevant fan, is heated to $200^{\circ} \mathrm{F}$., enters the lower ends of the tunnels and is forced over the trays by the fan. Stove distillate is used as a fuel and is burned by a Johnson Whirlwind burner. The cost of fuel is 30e per hour.

In the writer's opinion, the fan used should be larger and the heat introduced at about $160^{\circ} \mathrm{F}$. rather than $200^{\circ} \mathrm{F}$. Wire sereen trays should be used instead of wooden trays. For four Anderson tunnels a $5^{\prime}$ dise fan, 5 h.p. motor, $150^{\prime}$ of $12^{\prime \prime}$ pipe and a large burner could be used.

If wire screen trays $3^{\prime} \times 4^{\prime}$ were used in all Anderson evaporators now installed and if the heating capacity were increased, as Mr. Stone has done or by building furnace pits about $8^{\prime}$ deep $\times 15^{\prime}$ long beneath the tunnels and installing the heating system deseribed for the Oregon tunnel evaporator, good results could be obtained. So long as wooden trays are used, dissatisfaction is almost certain to result.

(d) Commercially Built Evaporators: Many very satisfactory and reliable evaporators are built and sold by California firms and by others. Some of these are of standard size and construction while others are built to order. Evaporators may be had for from about $\$ 400$ upward. Names of manufacturers can be furnished by the University upon request.

\section{SUMMARY AND CONCLUSIONS}

1. An evaporator is a good investment for the average California prune dry-yard. The past season has proved its utility.

2. In designing an evaporator, provision must be made for $(a)$ sufficient heat production, (b) sufficient radiating surface, $(c) \operatorname{good}$ air circulation, and $(d)$ control of temperature. Most evaporators now in use are deficient in one or more of these factors. Efficiency of heat utilization and convenience in operation are also desirable.

3. The Oregon tumnel evaporator, an air-blast evaporator for wooden trays, and the Young evaporator have been described in detail. General deseriptions have been given of the kiln evaporator, Watson- 


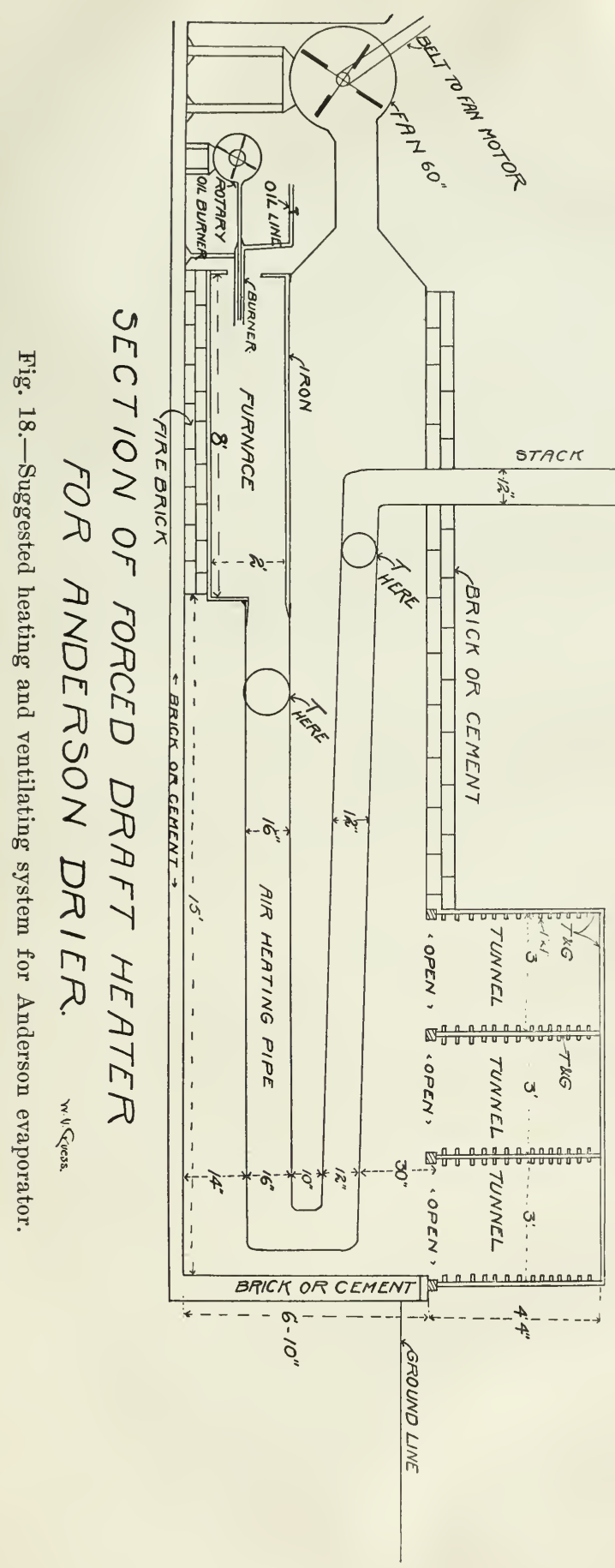


ville stack evaporator, and the Anderson evaporator. An installation by which the capacity of the Anderson evaporator may be increased has been described.

\section{RECOMMENDATION}

For the small dry-yard the Young type of evaporator or an evaporator of similar size is recommended. The Oregon tunnel evaporator would answer the needs of the average size yard. Where wooden trays are to be used, the air-blast evaporator will be best. 